\title{
MECHANISMS AND CONTROLLING CHARACTERISIICS OF THE CATALYTIC OXIDATION OF METHANE
}

Grant No. DE-FG02-86ER13580

\author{
TECHNICAL PROGRESS REPORT TO THE \\ BASIC ENERGY SCIENCE DIVISION OF THE U. S. DEPARTMENT OF ENERGY
}

June 15, 1990-December 14, 1992

DOE/ER/13580--T2

Submitted by:

DE93 005719

\author{
Kamil Klier, Principal Investigator \\ Gary W. Simmons, Co-Investigator \\ Richard G. Herman, Co-Investigator \\ Alfred C. Miller, Co-Investigator \\ Zettlemoyer Center for Surface Studies \\ and Department of Chemistry \\ Lehigh University \\ Bethlehem, PA 18015
}

The current program is a part of a broad based effort at Lehigh University to develop a scientific basis for conversion of methane, the principal component of natural gas, to synthesis gas $\left(\mathrm{CO} / \mathrm{CO}_{2} / \mathrm{H}_{2}\right)$, to oxygenates $\left(\mathrm{H}_{2} \mathrm{CO}\right.$ and $\left.\mathrm{CH}_{3} \mathrm{OH}\right)$, or to higher $\left(\mathrm{C}_{2}^{+}\right)$ hydrocarbons. The fundamental scientific issues revolve around the mode of activation of methane, starting with the C-H bond cleavage on the surface of a metal, oxide, or sulfide, the nature and stability of surface intermediates including various forms of carbon, and the control of oxidative or dehydrogenative conversion of the surface intermediates to useful products, i.e. hydrogen, carbon monoxide, formaldehyde, methanol, and higher hydrocarbons. In the case the oxidant is water, one deals with the steam reforming reaction that is technologically well-developed and is excluded from the proposed research. However, the use of carbon dioxide, oxygen, or air as oxidants is actively pursued. We have 


\section{DISCLAIMER}

This report was prepared as an account of work sponsored by an agency of the United States Government. Neither the United States Government nor any agency thereof, nor any of their employees, makes any warranty, express or implied, or assumes any legal liability or responsibility for the accuracy, completeness, or usefulness of any information, apparatus, product, or process disclosed, or represents that its use would not infringe privately owned rights. Reference herein to any specific con nercial product, process, or service by trade name, trademark, manufacturer, or otherwise does not necessarily constitute or imply its endorsement, recommendation, or favoring by the United States Government or any agency thereof. The views and opinions of authors expressed herein do not necessarily state or reflect those of the United States Government or any agency thereof. 
demonstrated in this work (1) that methane is readily activated at mild conditions $\left(100^{\circ} \mathrm{C}\right.$, 1 torr) over a relatively noble metal, Pd. This was observed using a stepped and kinked $\operatorname{Pd}(679)$ crystal (1), and other crystal faces are now being investigated to establish whether the cracking of the $\mathrm{C}-\mathrm{H}$ bond of methane on Pd is structure sensitive or structure insensitive. Oxygen chemisorption is extremely structure sensitive: weakly bonded, highly reactive oxygen overlayers form on $\operatorname{Pd}(100)$ surface (2), while strongly bonded, moderately reactive oxygen overlayers form on $\operatorname{Pd}(111)$ and $\operatorname{Pd}(679)$. Reaction of the weakly bonded oxygen with surface carbide gives rise to $\mathrm{CO}_{2}$ over clean $\mathrm{Pd}(100)$ but to $\mathrm{CO}$ over halogen-doped $\mathrm{Pd}(100)$ (3-5). The effect of halogens is primarily ensemble-controlling, or oxygen-supply restricting, but long range influence of surface $\mathrm{Cl}$ on the strength of the Pd-O bond has also been observed (3). Because the overall chemistry of methane activation with the subsequent oxidation gives rise to the very important oxidative reforming

$$
\mathrm{CH}_{4}+1 / 2 \mathrm{O}_{2} \underset{\mathrm{Pd} / \mathrm{Cl}}{\rightarrow} \mathrm{CO}+2 \mathrm{H}_{2}
$$

we plan to continue our study of this reaction in detail over $\operatorname{Pd}(100)$ (completed), $\operatorname{Pd}(111)$ (initiated), $\operatorname{Pd}(311$ ) (initiated), $\operatorname{Pd}(110)$ (to be initiated), and $\operatorname{Pd}(679)$ (completed), without and with the halogen modifiers.

To-date, we have centered our work on the methane/oxygen/chlorine/palladium system, and the issues addressed in our research are as follows:

- Is the $\mathrm{C}-\mathrm{H}$ bond rupture in methane sensitive to the structure of the metal surface?

- What is the primary activation mechanism at the lowest temperatures attainable?

- What are the conditions that leave carbon fragments monomeric, oligomeric, and polymeric?

- Given the known fact that oxygen chemisorption on Pd displays an enormous structure sensitivity and bond strength variations between $\mathrm{Pd}(100)$ and $\mathrm{Pd}(111)$, what is the reactive form of oxygen in methane oxidation? 
- What is the role of lateral interactions in $\mathrm{O}, \mathrm{CH}_{\mathbf{x}}$, and halogen overlayers on the reactivity of adsorbed molecules and the ccurse of surface catalyzed methane conversions?

- In the case of halogen promoters, what is the balance between the ensemble control of methane conversions, through-space dipolar repulsion, and through-metal electronic interactions in ad-layers?

- Can results of single crystal surface science research be used for predicting or at least characterizing the behavior of small metal catalyst particles?

In our recent work, some of the above issues were resolved, and some are close to resolution contingent upon additional catalytic, structural, and spectroscopic research to be yet carried out by us. New intrig ling experimental windows into the nature of surface reactions have opened up by combining high energy resolution XPS with photoelectron diffraction of core-level and valence-band (VB) emissions utilizing the SCIENTA ESCA facility at Lehigh University (LU). We describe herein specific accomplishments that pertain to the above listed issues.

Methane decomposition was shown to take place on the stepped/kinked $\operatorname{Pd}(679)$ surface at pressures $\geq 1$ torr and temperatures $\geq 400 \mathrm{~K}$ by a mechanism that is best explained by the Luntz-Harris model involving thermally-assisted tunneling $(1,6,7)$. The isotope effect for $\mathrm{CH}_{4} / \mathrm{CD}_{4}$ decomposition at $400 \mathrm{~K}$ is predicted to be $\approx 7.7$ from initial reactive sticking probabilities and $\mathrm{E}_{\mathrm{a}}\left(\mathrm{CH}_{4}\right)=10.7 \mathrm{kcal} / \mathrm{mol}(1)$, utilizing the Luntz-Harris theory $(6,7)$. The amount of monomeric carbon found at $400 \mathrm{~K}$ is equivalent to the step area, indicating a significant role of surface defects in methane decomposition. At $600 \mathrm{~K}$, however, the surface carbon from methane oligomerizes into clusters, leaving $75 \%$ of the Pd surface free for further reactions. The methane decomposition with subsequent carbon oligomerization is represented by a pathway diagram (1) shown in Figure 1.

Based on this picture, monomeric carbon can be "frozen" because of the existence of 


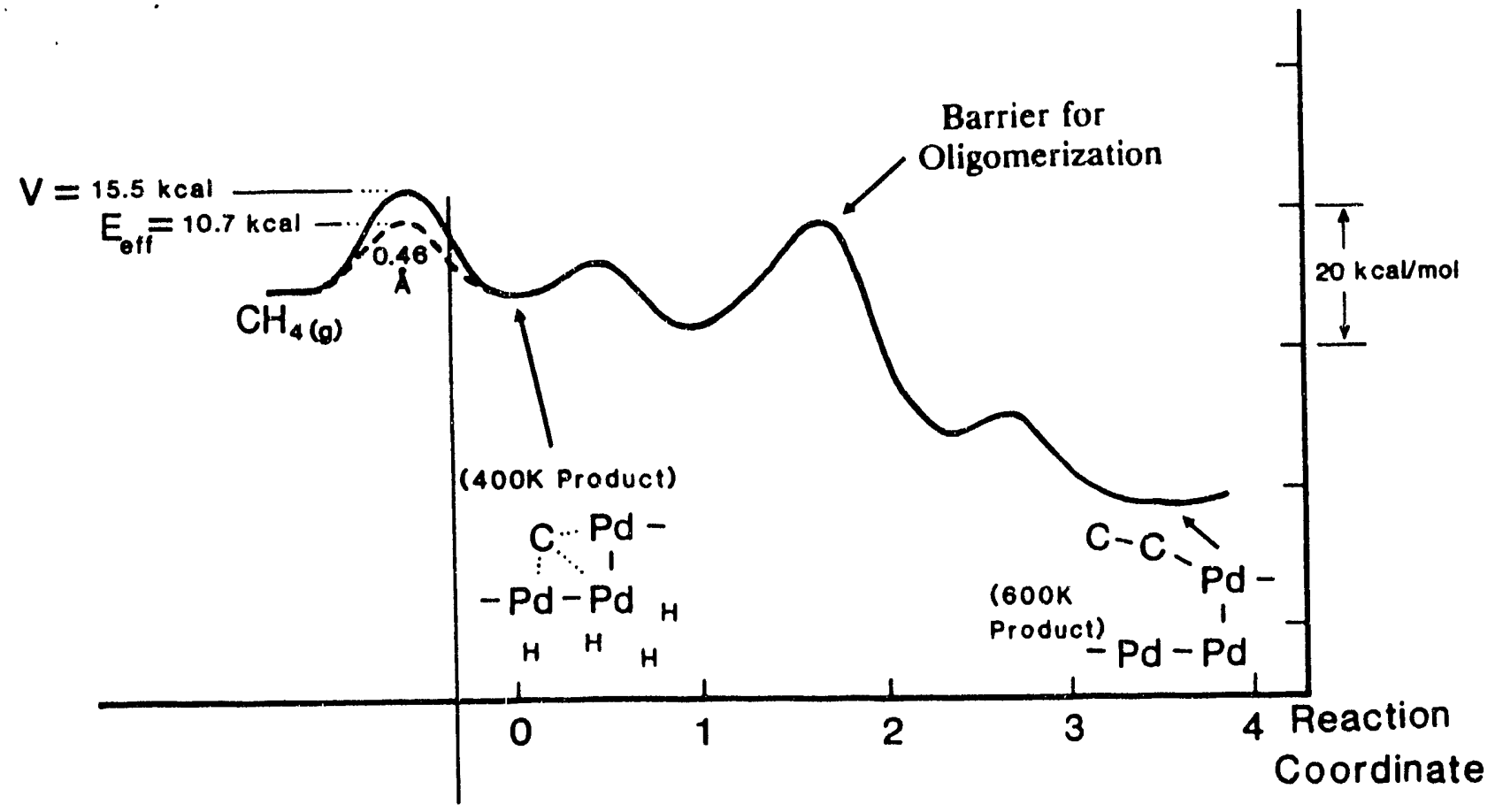

FIGURE 1. A schematic of the energetic pathway for the decomposition of methane and C-C bond formation leading to clustering on the $\operatorname{Pd}(679)$ surface. The right side of the figure is the calculated energy as a function of surface reaction coordinate for C-C bond formation on a fcc (111) surface as adapted from Koerts and van Santen (8). The reaction coordinate corresponds to a carbon atom rolling up onto another carbon atom so that the first atom is no longer in contact with the surface. The energies for $\mathrm{CH}_{4}$ decomposition shown on tiiz left side of the figure correspond to the experimental apparent activation energy $(10.7 \mathrm{kcal} / \mathrm{mol})$ found in this work (dash line) and the calculated energy for $\mathrm{CH}_{4}$ decomposition via thermally assisted tunneling (solid line) (7).

an energy barrier for oligomerization. New results for $\operatorname{Pd}(311)$ show essentially the same behavior as that of $\operatorname{Pd}(679)$, but the smooth $\operatorname{Pd}(111)$ has to be re-investigated to finally establish the sensitivity of methane decomposition to the presence of step defects. We had a set-back with $\operatorname{Pd}(111)$ at the beginning of this research due to delivery of wrong, contaminated, and structurally imperfect crystals. The square $\operatorname{Pd}(100)$ is currently being investigated, too, and $\operatorname{Pd}(110)$ is planned for the near future.

The oxygen reactant displays a very large range of $\mathrm{Pi}-\mathrm{O}$ bond strengths depending on the exposed crystal face. $\operatorname{Pd}(111), \operatorname{Pd}(679)$, and $\operatorname{Pd}(311)$ bind oxygen quite strongly and 
diffusion into the metal occurs at $900 \mathrm{~K}$ before desorption $(9,10)$. However, the subsurface oxygen causes the subsequent surface bonding $\mathrm{Pd}-\mathrm{O}$ to be weak and a new reactive state of surface oxygen is generated on $\operatorname{Pd}(111)$ and $\operatorname{Pd}(679)$ in this way $(9,10)$. The $\operatorname{Pd}(100)$ face binds oxygen weakly into the well-known $\mathrm{c}(2 \times 2), \mathrm{p}(2 \times 2)$, and $(\sqrt{5} \times \sqrt{5}) \mathrm{R} 27^{\circ}(\theta=0.8)$ structures. However, new surface phase transformations have been discovered (2) that may have bearing on catalysis. For example, the $c(2 \times 2)$ structure disproportionates around $500 \mathrm{~K}$ into a rare, mobile phase and the dense $(\sqrt{5} \times \sqrt{5}) \mathrm{R} 27^{\circ}$ phase before any oxygen desorbs. A summary (11) of the behavior of the oxygen overlayer on $\mathrm{Pd}(100)$ is shown in Figure 2. A complete phase diagram of the O-Pd(100) system (2) is shown in Figure 3.

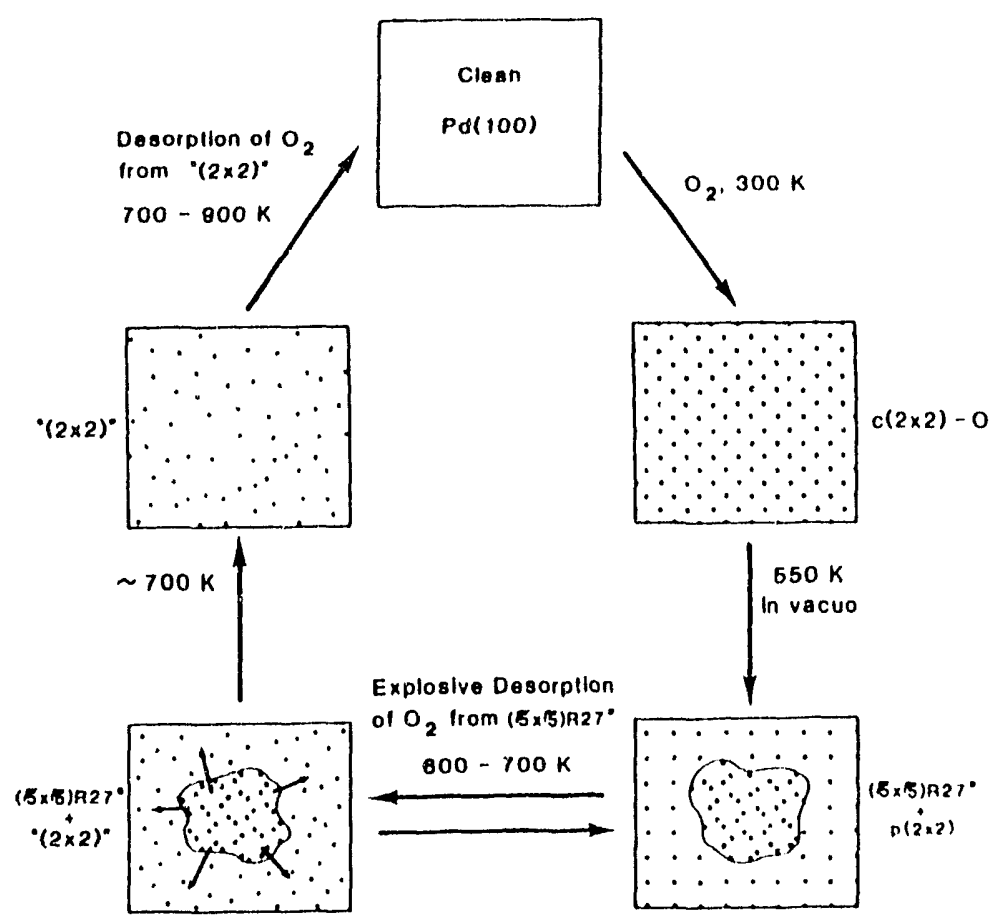

FIGURE 2. Summary (11) of the whole sequence of events occurring upon adsorption and thermal desorption of oxygen from the clean $\operatorname{Pd}(100)$ surface.

The equilibration kinetics have been successfully modeled (11) and lateral dipole interactions accounted for a strong dependence of energy of desorption from the rare phase 


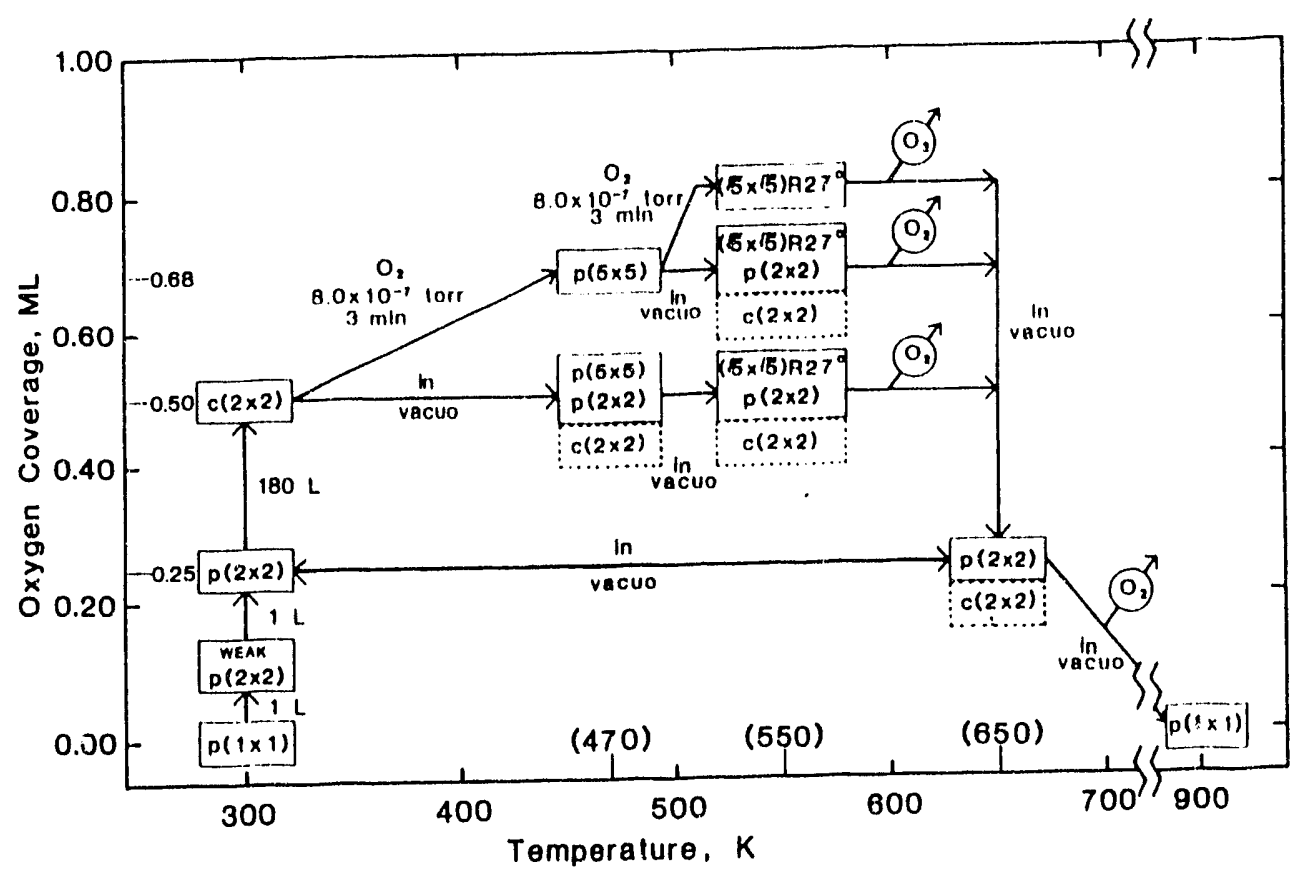

FIGURE 3. Summary of the oxygen phases observed as a function of surface temperature and oxygen exposures (2). LEED patterns of the phases enclosed by a solid line were observed at room temperature. The dotted line around the $c(2 \times 2)$ phase indicates that evidence for this phase was observed at the temperature indicated.

on coverage. The Pd-O dipole moment derived from the data, $2.85 \mathrm{D}$, corresponds to an effective charge on the surface oxygen of $-0.6 \mathrm{e}^{-}$(7). The formation of the rather large surface dipole is confirmed by $\mathrm{Pd} 3 \mathrm{~d}_{5 / 2}$ and $\mathrm{Pd} 3 \mathrm{~d}_{3 / 2}$ core level shifts for the $\mathrm{c}(2 \times 2)$ structure as shown in Figure 4 (12), where $\mathrm{Pd}_{\mathrm{b}}=$ bulk palladium atoms and $\mathrm{Pd}_{\mathrm{s}}=$ surface palladium atoms adjacent to oxygen.

Since the $3 \mathrm{~d}$ emissions of the $\mathrm{Pd}^{\mathrm{II}}$ ions in $\mathrm{PdO}$ show a $1.4 \mathrm{eV}$ shift to higher binding energies relative to $\mathrm{Pd}^{\circ}$, the observed $0.4 \mathrm{eV}$ shift indicates electropositive surface $\mathrm{Pd}$ atoms bonded to $\mathrm{O}^{\delta-}$. The charge on $\mathrm{Pd}_{\mathrm{a}}$ in $\mathrm{c}(2 \times 2) \mathrm{O}-\mathrm{Pd}(100)$ is $+0.3 \mathrm{e}^{-}$if $\mathrm{PdO}$ is essentially ionic, consistent with $-0.6 \mathrm{e}^{-}$on oxygen in the $\mathrm{c}(2 \times 2)$ structure in which the $\mathrm{Pd}: \mathrm{O}$ ratio is $2: 1$. The exact location of the $\mathrm{Pd}_{\mathrm{a}}$ and $\mathrm{Pd}_{\mathrm{b}}$ in the oxygen overlayer structures is being determined by XPS diffraction of the $3 d_{5 / 2}$ photoelectrons emitted from each of these species. This requires careful acquisition and interpretation of angle-resolved XPS data. The structural 
work on clean $\operatorname{Pd}(100)$ has been published by us (13) with the simple result that forward focused diffraction dominates and the $\mathrm{Pd}(100)$ plane is unrelaxed to 3-4 layers, to within $0.02 \AA$.
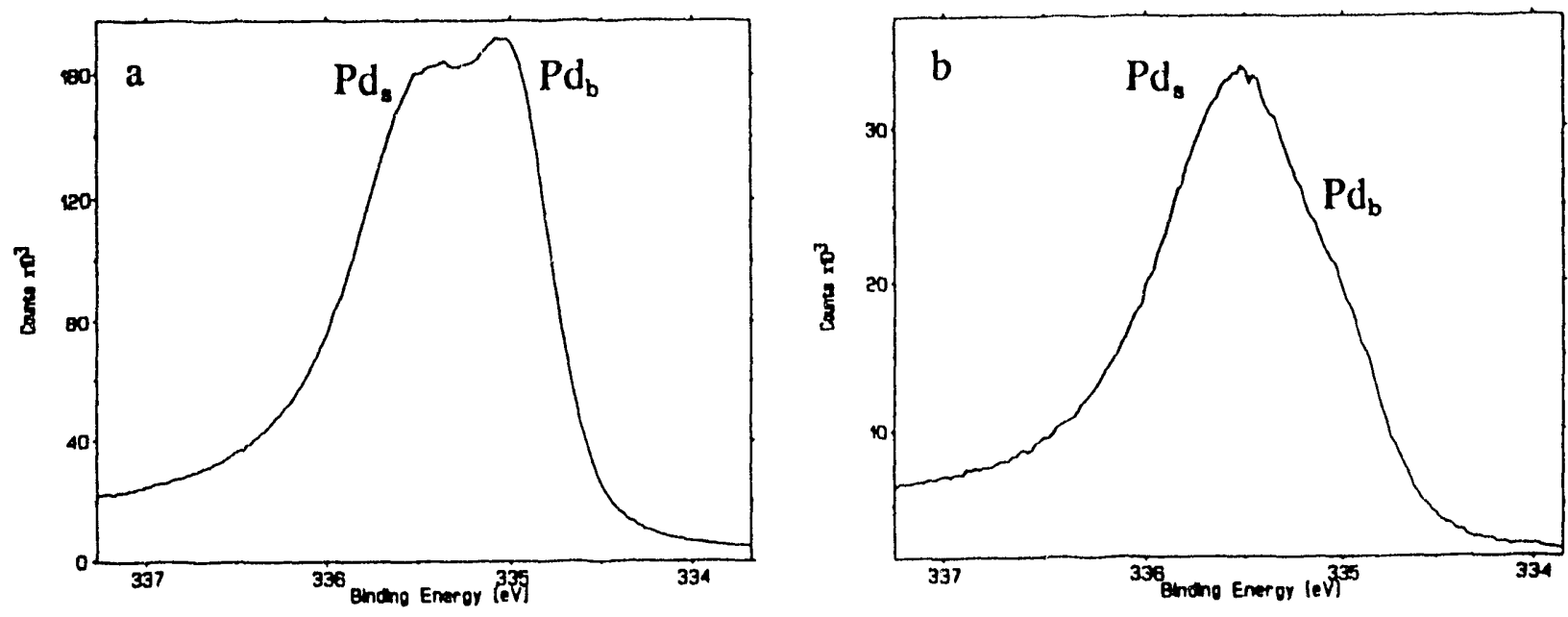

FIGURE 4. The $\mathrm{Pd} 3 \mathrm{~d}_{5 / 2}$ line from $\mathrm{c}(2 \times 2) \mathrm{O}-\mathrm{Pd}(100)$ (a) at normal ernission and (b) emission at $85^{\circ}$ from the normal.

The ARXPS diffraction of the $c(2 \times 2) O-P d(100)$ is shown in Figure 5, for one azimuth, $<100>$. In this direction, $\mathrm{Pd}_{\mathrm{b}}$ diffracts off other $\mathrm{Pd}$ bulk atoms to within 3-4 layers, off the

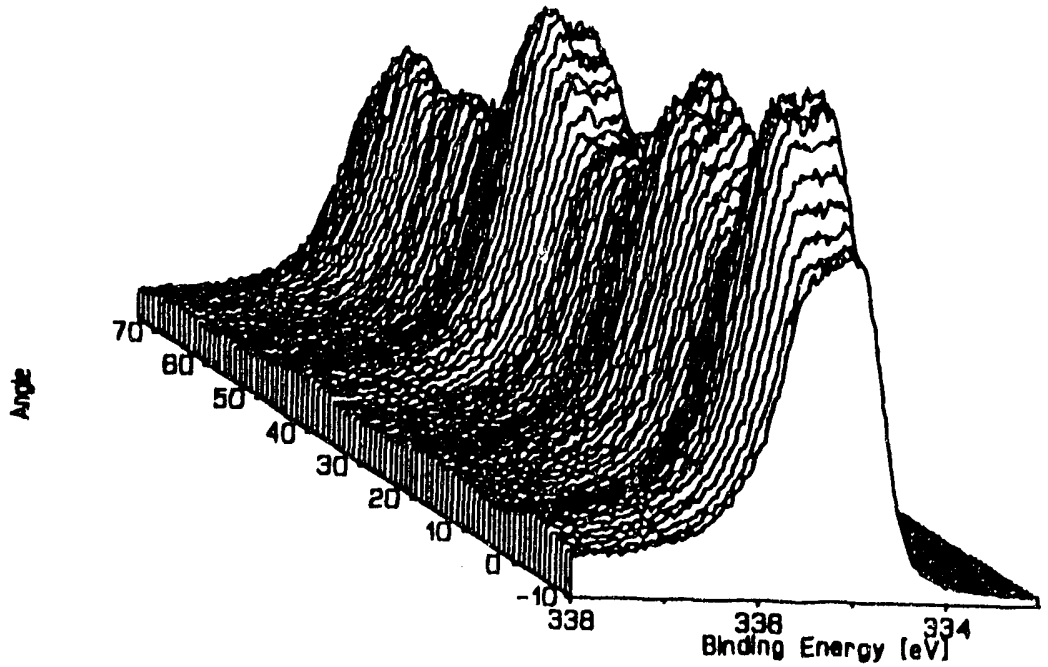

FIGURE 5. Angle-resolved X-ray photoemission from the $c(2 \times 2) \mathrm{O}-\mathrm{Pd}(100)$

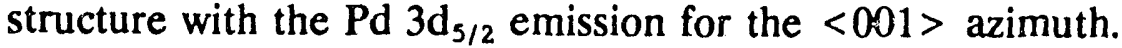


surface $\mathrm{Pd}_{\mathrm{s}}$ atoms, and off the surface oxygen in the four-fold holes of the $\mathrm{c}(2 \times 2)$ structure. $\mathrm{Pd}_{\mathbf{s}}$ photoelectrons diffract in the forward direction only off the surface oxygen, but their angle resolved pattern is also influenced by backscattering (12). The forward focused directions of the $\mathrm{Pd}_{b}$ and $\mathrm{Pd}_{\mathrm{s}}$ emissions are represented in Figure 6.

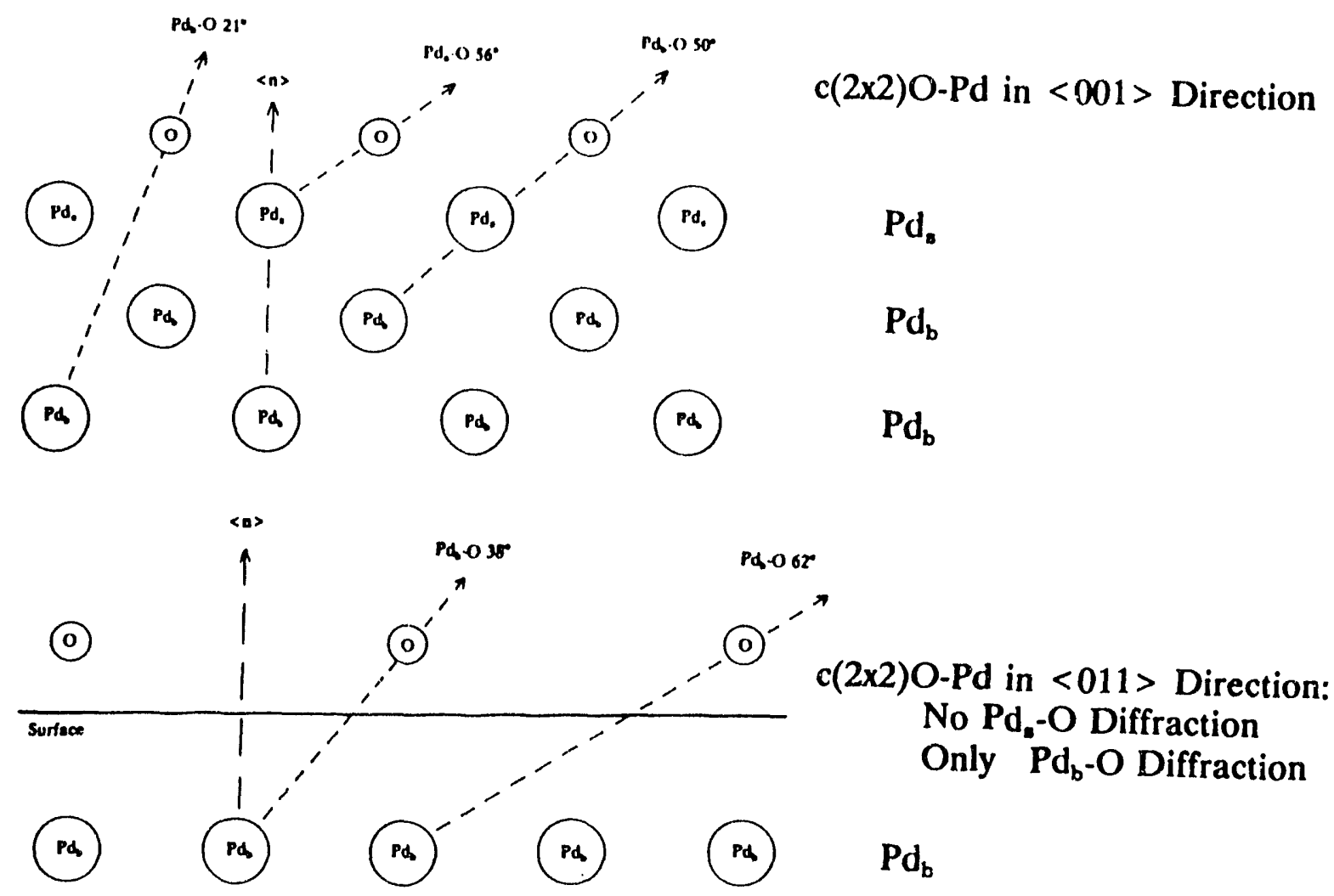

FIGURE 6. Directions of forward focusing in the $c(2 \times 2) \mathrm{O}-\mathrm{Pd}(100)$ overlayer structure. Of the principal azimuths, $\mathrm{Pd}_{\mathrm{s}}-\mathrm{O}$ forward focusing occurs in the $<001>$ direction but not along the $<011>$ azimuth.

Data represented in Figure 5 and the analogous data along the $<110\rangle$ azimuth contain complete information about the $\mathrm{c}(2 \times 2) \mathrm{O}-\mathrm{Pd}(100)$ structure including positions of the $\mathrm{O}$ and $\mathrm{Pd}$ atoms down to several layers. Note the excellent quality of the angular variation of XPS intensity data in Figure 5, which is enabled by the SCIENTA's rotating anode, high resolution monochromator, front-of-the-analyzer electron optics, and very high resolution/ 
throughput analyzer (14). The angle-resolved XPS has in fact been done in this laboratory also for very weak photoemissions such as those from the valence band (VB) and those involving electron energy losses and interactions with surface plasmons. A complete geometric/electronic picture is emerging for any adsorbate structure from this research. Since photoelectron diffraction is sensitive to local structures (15), disordered overlayers can be studied too.

A UV source was incorporated in the SCIENTA instrument in 1991 for detailed studies of electronic structure of valence bands in chemisorbed layers of reactants. This type of experiment provides for testing theory and identifying electron orbitals that participate in chemisorption by determining energy dispersion E(k) by ARUPS (16). An example from this laboratory is shown in Figure 7, for comparison purposes again for the $c(2 \times 2) O \cdot \operatorname{Pd}(100)$ layer. The ver" large dispersion is clearly seen from peak shifts with the emission angle, and changes upon oxygen chemisorption occur near the $M$ point of the Brillouin Zone (17).

Solid state theoretical calculations performed in this laboratory have identified the observed effect as bonding interaction of $\mathrm{O} 2 \mathrm{p} \|$ orbitals with $\mathrm{Pd} 4 \mathrm{~d}_{\mathbf{z x}, \mathbf{y z}}$ orbitals that dominate the surface states of Pd near the M-point of the Brillouin Zone (17). While this result is not unexpected, the ARUPS experiment can provide good qualitative indication of the nature of surface bonding for more complex structures.

We now turn to the discussion of the effects of spectator chemisorbates, in our case of halogens, on catalytic reactions related to methane oxidations. First, $\mathrm{Cl}$ was found to lower the Pd-O bonding energy by a long range effect over average 2-3 Pd-Pd distances (3). This is thought to be due to the "through-space" dipole repulsion in view of such repulsions being important in the oxygen overlayer only (11). The experimental test for this picture entails the determination of $\mathrm{Pd} 3 \mathrm{~d}$ core level shifts in $\mathrm{Pd} / \mathrm{O} / \mathrm{Cl}$ overlayers, similarly to that 

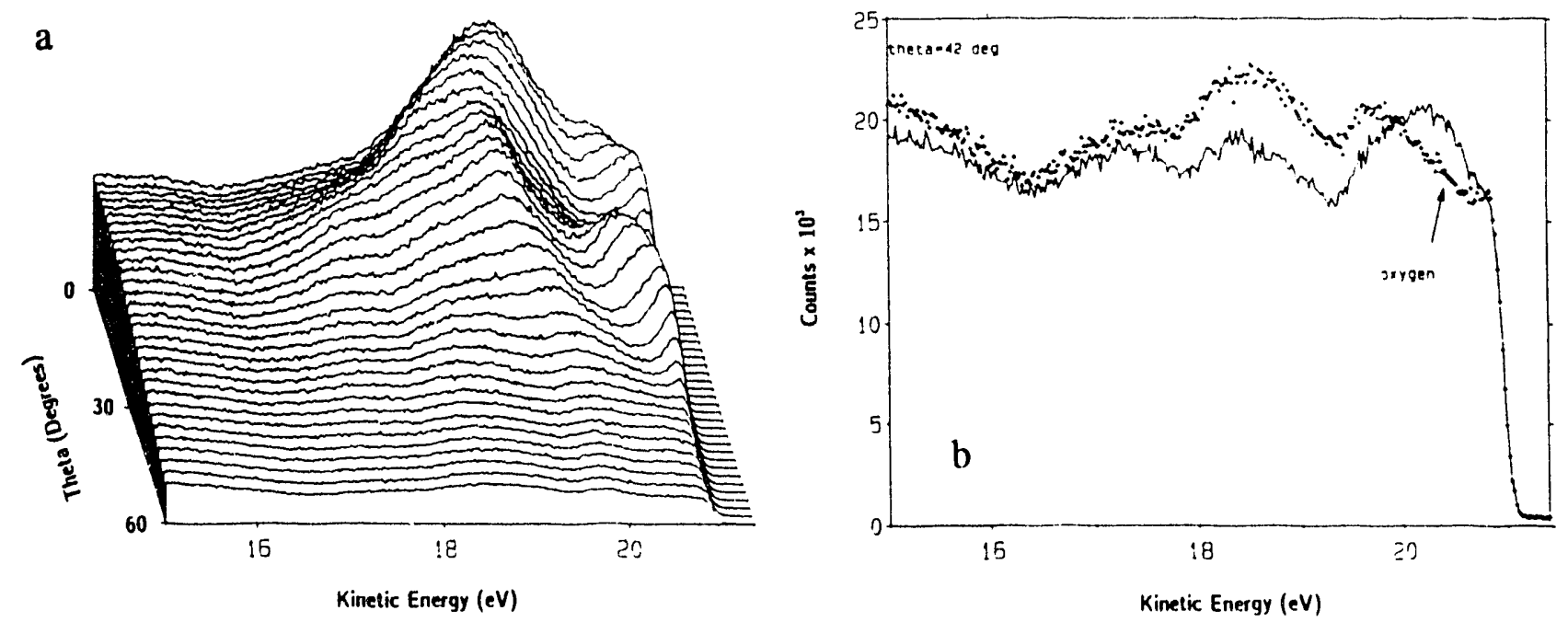

FIGURE 7. (a) A 3-D representation of the ARUPS spectra of $c(2 \times 2) O$ $\mathrm{Pd}(100)$ using the $\mathrm{He} \mathrm{I}$ excitation at $21.22 \mathrm{eV}$. Shifts in the peak position are noted as a function of emission angle $\theta$. (b) UPS valence band spectra $(\theta=$ $\left.42^{\circ}\right)$ of $\mathrm{c}(2 \times 2) \mathrm{O}-\mathrm{Pd}(100)$ (crosses) compared with clean $\mathrm{Pd}(100)$ (solid line).

shown for $\mathrm{Pd} / \mathrm{O}$ in Figure 4. In the case of long range through-metal electronic interactions, the $\mathrm{Pd}_{\mathrm{s}} 3 \mathrm{~d}$ core level shift will not remain constant with $\mathrm{Cl}$ concentration and vice versa.

Aside from the lateral interactions influencing the $\mathrm{Pd}-\mathrm{O}$ bond strengths, the halogen causes an ensemble controlling effect on reactive surface oxygen supply to a substrate. In the case of carbon, selectivity of its oxidation is switched from $\mathrm{CO}_{2}$ to $\mathrm{CO}$ product by small (5-12\% $\mathrm{Cl}$ coverage) amounts of the halogen (3-5). In our previous work, the halogen was introduced by dissociative chemisorption of dichloromethane that generated a semi-random distribution of $\mathrm{Cl}$ atoms in the available four-fold holes of the $\mathrm{Pd}(100)$ surface (3). What is proposed in our continuation proposal is to explore two-dimensional shape selectivity in pockets of $\mathrm{Cl}$ atoms generated by surface dissociation of cyclic chlorocarbons, thus defining reactive metal ensembles both by size and by shape.

We have enhanced our instrumentation capabilities during the current research project. This includes the purchase, installation, and use of a UPS source on the SCIENTA- 
300 that allows us to carry out ARUPS surface analyses, e.g. the data in Figure 7 for the valence band of Pd. In addition, we have designed, had fabricated for us, installed, and used a high pressure adsorption/reaction cell that is contained inside an UHV instrument that contains LEED, Auger, TPD/MS analytical attachments (18) for single crystal research.

High performance of the SCIENTA ESCA-300 instrument was verified and further improved to provide $0.25 \mathrm{eV}$ energy resolution, the determination of the tiansmission function, analysis of very small amounts of dopants in oxides $(19,20)$, and accuracy of core level peak position to $10^{-2} \mathrm{eV}$. In this work, several types of flood guns were tested for charge neutralization, and we have obtained very good performance with insulating and narrow-gap and wide-gap semicon scing solids, along with accurate resolution on the Fermi edge of metals. Valence band XFS spectroscopy and structural work involving very low level core level emissions, as well as plasmons and shake-up peaks, are carried out routinely with the SCIENTA ESCA-300 instrument.

Very small amounts of dispersed $\mathrm{Pd}$ in the form of $\mathrm{SiO}_{2}$-supported $\mathrm{Pd}(21)$ and $\mathrm{Pd}$ supported on $\mathrm{Cu} / \mathrm{Fe} / \mathrm{ZnO}$ catalysts (22) have been tested for selective methane oxidation by continuous flow experiments. The tested catalysts were subsequently analyzed by high resolution XPS, and in some cases these catalysts have been shown to possess totally carbonfree surfaces.

In the area of reaction mechanisms of conversion processes that produce oxygenates, Klier gave a plenary lecture at the Conference on Theoretical Aspects of Catalysis in Cracow, Poland (23) and the Brdicka Lecture at the Czechoslovak Academy of Sciences in Summer 1992 (24). With respect to the reaction mechanisms involving methanol, we have presented evidence for molecular dispersion of a cesium promoter with its counterion on the $\mathrm{Cu} / \mathrm{ZnO}$ catalyst, over the surface concentration range of 0.05 tc $0.90 \mathrm{Cs}$ per $\mathrm{Zn}$, and 
we provided a theoretical account for the $C_{n} \rightarrow C_{n+1}$ alcohol synthesis steps (25).

Installation of a new IBM RISC $6000 / 350$ computer dedicated to our research has been completed. Several computational program packages have been adapted for use in the IBM RISC $6000 / 350$ workstation environment. This was accomplished by Mr. Yang Gao (summer undergraduate research program student) working with Dr. Emir Gürer (26). These include (i) the solid state adaptation of the Extended Hückel Molecular, Crystal and Properties Package from the Quantum Chemistry Program Exchange and (ii) the state-of-the art computation package for XPS diffraction by C. S. Fadley. The CRYSTAL92 package by R. Dovesi, V. R. Saunders, and C. Roetti of the University of Torino will also be loaded onto the IBM RISC $6000 / 350$ workstation and ancillary computers in January 1993 . The precision and size consistency of the computations have been vertified and computational speeds have been compared with the Y-MP/832 supercomputer at the University of Pittsburgh using a standard test program.

\section{LITERATURE REFERENCES}

1. Wang, Y.-N., Herman, R. G., and Klier, K., Surface Sci., 279, 33 (1992).

2. Simmons, G. W., Wang, Y.-N., Marcos, J. A., and Klier, K., J. Phys. Chem., 95, 4522 (1991).

3. Wang, Y.-N., Marcos, J. A., Simmons, G. W., and Klier, K., L. Phys. Chem., 94, 7597 (1990).

4. Wang, Y.-N., Simmons, G. W., Marcos, J. A., and Klier, K., in "Preprints, Symp. on Methane Activation, Conversion, and Utilization," PACIFICHEM'89: Intern. Chen. Cong. of Pacific Basin Societies, Honolulu, HI, 89 (Dec. 1989).

5. Klier, K., Simmons, G. W., Wang, Y.-N., and Marcos, J. A., in "Structure-Activity Relationships in Heterogeneous Catalysis," ed. by R. K. Grasselli and A. W. Sleight, Elsevier, Amsterdam, 309 (1991).

6. Luntz, A. C. ard Harris, J., Surface Sci., 258, 397 (1991). 
7. Harris, J., Simons, J., Luntz, A. C., Mullins, C. B., and Rettner, C. T., Phys. Rev. Lett., 67, 652 (1991).

8. Koerts, T. and van Santen, R. A., Catal, Lett., 6, 49 (1990).

9. Wang, Y.-N., Herman, R. G., Hess, J. S., and Klier, K., manuscript under revision.

10. Conrad, H., Ertl, G., Kuppers, J., and Latta, E. E., Surface Sci., 65, 215 (1977).

11. Klier, K., Wang, Y.-N., and Simmons, G. W., J. Phys, Chem.; in press.

12. Gürer, E. and Klier, K., manuscript in preparation.

13. Gürer, E. and Klier, K., Phys, Rev, B, 46, 4884 (1992).

14. Chaney, R. L. and Simmons, G. W., R\&D Magazine, 32, 82 (1990).

15. Fadley, C. S., in "Synchrotron Radiation Research: Advances in Surface and Interface Science, Vol. 1: Techniques," ed. by R. Z. Bachrach, Plenum Press, New York, 421 (1992).

16. Smith, N. V. and Traum, M. M., Phys. Rev, B., 11, 2087 (1975).

17. Gürer, E. and Klier, K., to be submitted.

18. Wang, Y.-N., McAllister, R., Herman, R. G., Simmons, G. W., and Klier, K., Rev. Sci. Instrum., 63, 5767 (1992).

19. Sojka, Z., Herman, R. G., and Klier, K., J. Chem. Soc. Chem. Commun., 185 (1991).

20. Sojka, Z. and Klier, K., J. Electron Spectrosc. Relat. Phenom, 60, 155 (1992).

21. Di Cosimo, J. I., Herman, R. G., and Klier, K., Proc. Argentina Catal. Soc., 2 pp (1991).

22. Sojka, Z., Herman, R. G., Klier, K., and Di Cosimo, J. I., 12th North Amer, Meeting of the Catal. Soc., Abstr. No. B-16 (1991).

23. Klier, K., Catal. Today; manuscript in preparation.

24. Klier, K., Brdicka Lecture, Czechoslovak Academy of Sciences; submitted.

25. Klier, K., Herman, R. G., Himelfarb, P. B., Young, C.-W., Hou, S., and Marcos, J. A., Proc. 10th Intern. Congr. Catal, O100 (6 pp) (1992).

26. Gao, Y., Gürer, E., and Klier, K., documentation available. 

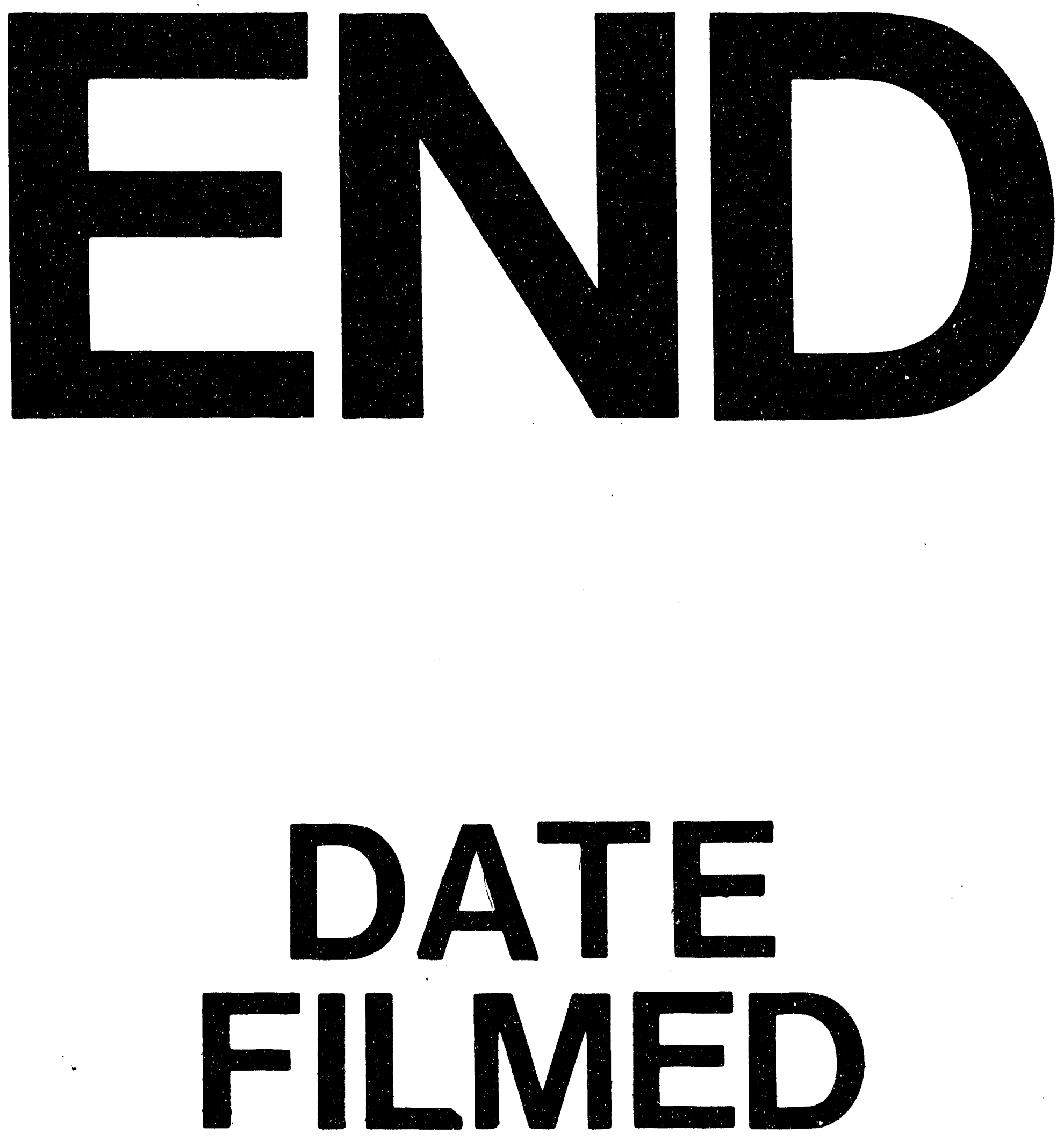

覀

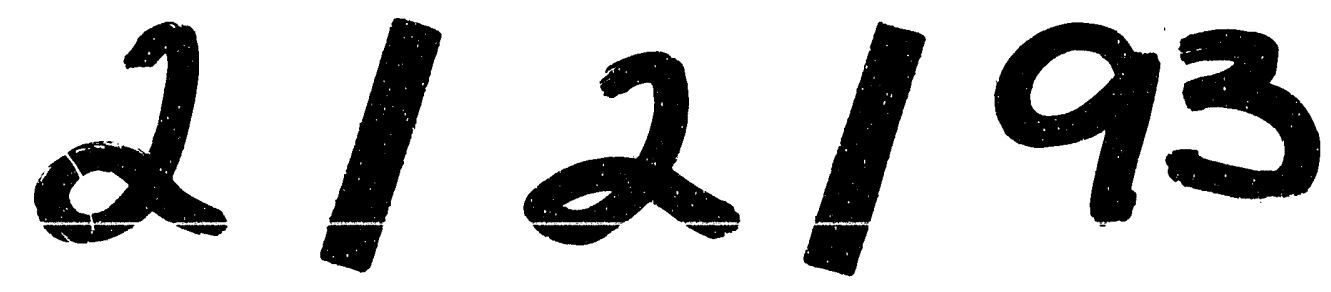




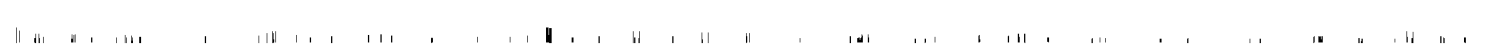

$=$
-

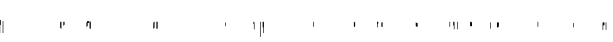

